\title{
Analysis of Performance characteristics of an Internal Combustion Engine with Thermal barrier coated piston
}

\author{
A.Gowtham Rajan ${ }^{1}$, A.Bharath Nithish ${ }^{2}$, S.Ramprakaash ${ }^{2}$, K.Vithyasagar $^{2}$ \\ ${ }^{1}$ Assistant Professor, Department of Automobile Engineering, School of Automotive and Mechanical \\ Engineering, Kalasalingam Academy of Research and Education, India, gowthamrajan16@gmail.com \\ ${ }^{2}$ Student, Department of Automobile Engineering, School of Automotive and Mechanical Engineering, \\ Kalasalingam Academy of Research and Education, India, bhax19@gmail.com, ramprakaash1234@gmail.com, \\ vithyasagar53@gmail.com
}

\begin{abstract}
Investigation of the thermal analysis of a conventional (uncoated) diesel piston made up of Aluminum silicon alloy was carried out in this present study. Secondly, thermal analysis was performed on piston crown, coated with $20 \%$ $\mathrm{Al}_{2} \mathrm{O}_{3} \& 80 \%$ Yttria Stabilized Zirconia material. TBC comes with two layers; the first layer is a bond coating with $\mathrm{NiCoCrAlY}$ compound. The second layer with TBC material (20\% Aluminum oxide \& 80\% Yttria Stabilized Zirconia). The method of multilayer coating was achieved through the Air Plasma spraying technique. Using the coated piston the required temperature in the combustion chamber will be maintained. This will reduce the heat loss to the piston. This reduction in the heat loss will be used to burn the un-burnt gases thereby reducing the polluted exhaust gases. Result will be shown as the thermal efficiency of the coated piston at full load will be increased than uncoated piston and the oxides of nitrogen will be increased.
\end{abstract}

Key words : Air Plasma Spray, Aluminum oxide, Thermal barrier coating, Yttria stabilized zirconia.

\section{INTRODUCTION}

The Low Heat Rejection Engine (LHRE) is the concept of coating the combustion chamber walls and piston crown with ceramic or thermal barrier coating. Generally, the LHR Engine is used to improve the fuel economy. Coating the piston crown with thermal barrier coating will increase the internal combustion engine efficiency and also reduces the harmful pollutants released to the environment. Thermal barrier ceramic coatings are used in most of the automotive components in order to reduce the heat loss. These thermal barrier coatings are already used in exhaust manifold, exhaust headers, downpipe and tailpipes also used in piston crown to reduce the heat loss from the engine [1-5]

Thermal barrier coating is dual bond coating process first layer is a bond coat consist of NiCrAlY compound and then the ceramic top coat. The function of ceramic top coat is to reduce the temperature of the underlying, less heat resistant metal part. Coating the piston with several thermal barrier coating increases the feature of the material with less weight and volume. Typical piston materials are light alloys, cast iron, nodular cast iron, and alloyed steels. The pistons for high-speed engines are primarily made of aluminum silicon alloys. The aluminum alloy material which is used in the design of pistons has good plasticity and can good durability with greater stress. However, the high temperature carrying capacity of the piston is limited and it cannot withstand high temperature. Further, the TBCs can provide thermal fatigue protection for the piston crown and can withstand some amount of heat. However, the coated piston had a higher surface hardness and wear resistance [6-9]. Partially stabilized zirconia is known to have a fracture toughness of 5.8-9 MPa [10].

The objective of the present work is to examine TBC coating in piston crown and to find its performance. The first part of the research is to find the suitable thermal barrier coating material with perfect ratio and coating it in the piston crown by plasma spray method. And then the coated piston is compared to stock piston by performing performance test, combustion test and emissions.

\section{MATERIALS AND METHODS}

In comparing with other ceramic material, yttria stabilized zirconia (YSZ) and partially stabilized zirconia (PSZ) has better toughness, low thermal conductivity, thermal shock resistance, heat withstanding strength and a thermal expansion coefficient nearer to steel and cast iron. Yttria oxide sometimes known as yttria $\left(\mathrm{Y}_{2} \mathrm{O}_{3}\right)$, is in the form of white powder which is an air-stable, solid substance with spherical morphology [13]. Its melting point is high $\left(2425^{\circ} \mathrm{C}\right)$ and has chemical stability, low coefficient of thermal expansion and low cut off energy of photons. And also, the major use of yttrium oxide nano particles is seen in inorganic synthesis. Aluminum oxide, a chemical compound of aluminum and oxygen, that is significantly used to produce aluminum metal which owes hardness and high melting point. 


\subsection{Material Properties}

The properties of Thermal barrier coating materials of $\mathrm{Al}_{2} \mathrm{O}_{3}$, $\mathrm{Y}_{2} \mathrm{O}_{3}$ and $\mathrm{ZrO}_{3}$ was mentioned the Table 1 [15-16]. Both physical and chemical properties of the coating materials was found to be suitable for withstanding the high heat. Further the material utilized for coating was inspected for properties, before application of thermal coating onto the piston[11-12].
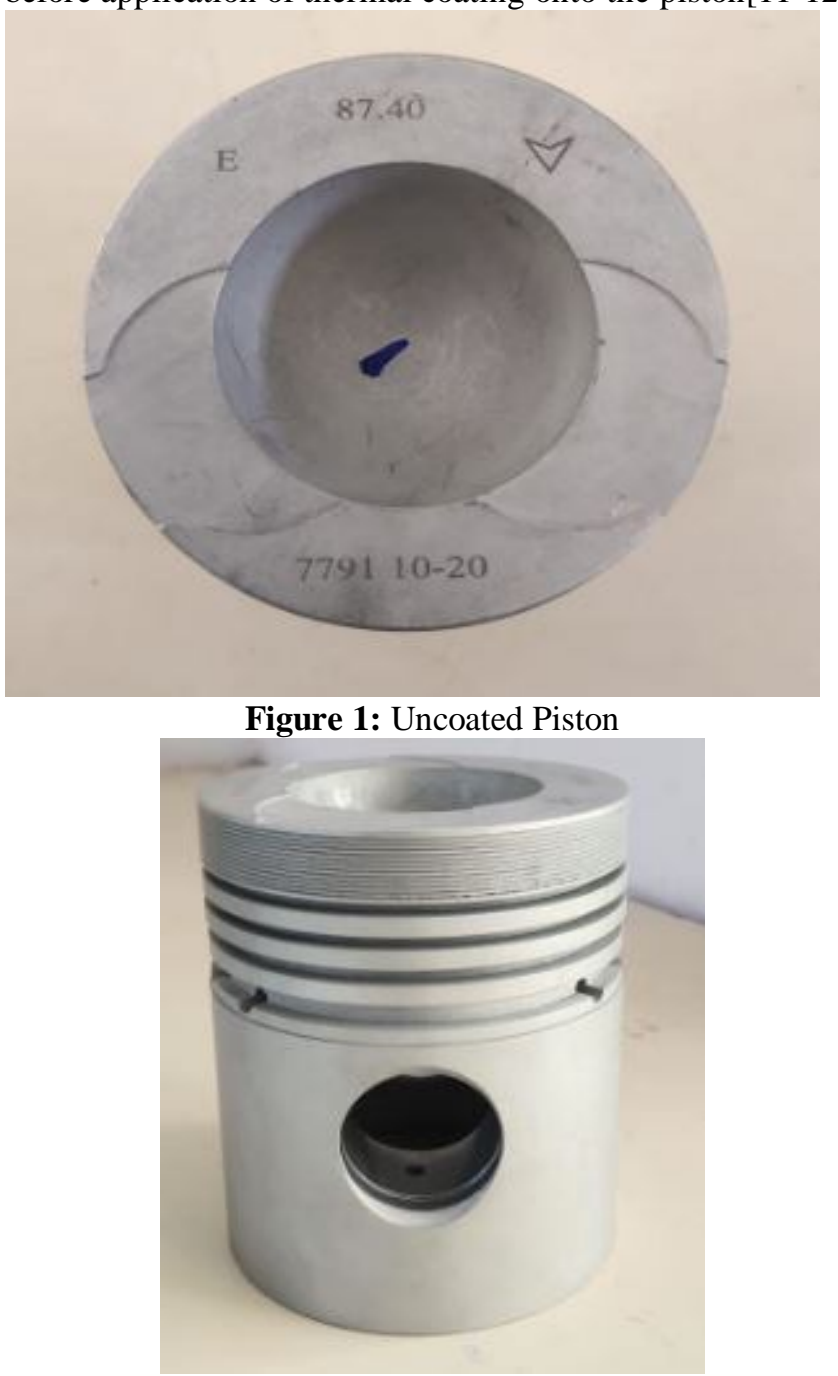

Figure 2: Side view of coated piston

Table 1: Properties of TBC Materials[15]

\begin{tabular}{|l|l|l|l|}
\hline Properties & $\mathbf{A l}_{\mathbf{2}} \mathbf{O}_{\mathbf{3}}$ & $\mathbf{Y}_{\mathbf{2}} \mathbf{O}_{\mathbf{3}}$ & $\mathbf{Z r O}_{\mathbf{3}}$ \\
\hline $\begin{array}{l}\text { Thermal } \\
\text { conductivity }\end{array}$ & $\begin{array}{l}20-30 \\
\mathrm{~W} / \mathrm{mK}\end{array}$ & $17 \mathrm{~W} / \mathrm{mK}$ & $2 \mathrm{~W} / \mathrm{mK}$ \\
\hline Hardness & $15 \mathrm{GPa}$ & $9 \mathrm{GPa}$ & $\begin{array}{l}13.24 \\
\mathrm{GPa}\end{array}$ \\
\hline Melting point & $2072^{\circ} \mathrm{C}$ & $2425^{\circ} \mathrm{C}$ & $2715^{\circ} \mathrm{C}$ \\
\hline Density & 3965 & $5010 \mathrm{Kg} / \mathrm{m}^{3}$ & $\begin{array}{l}5680 \\
\mathrm{Kg} / \mathrm{m}^{3}\end{array}$ \\
\hline Specific Heat & $\begin{array}{l}451 \mathrm{~m}^{3} \\
\mathrm{~J} / \mathrm{Kg}-\mathrm{K}\end{array}$ & $440 \mathrm{~J} / \mathrm{Kg}-\mathrm{K}$ & $\begin{array}{l}420 \\
\mathrm{~J} / \mathrm{Kg}-\mathrm{K}\end{array}$ \\
\hline $\begin{array}{l}\text { Thermal } \\
\begin{array}{l}\text { Expansion value } \\
\left(0-1200^{\circ} \mathrm{C}\right)\end{array}\end{array}$ & $\begin{array}{l}4.5 \times 10^{-6} \\
\mathrm{~K}^{-1}\end{array}$ & $8.1 \times 10^{-6} \mathrm{~K}^{-1}$ & $\begin{array}{l}11 \times 10^{-6} \\
\mathrm{~K}^{-1}\end{array}$ \\
\hline
\end{tabular}

\subsection{Air Plasma Spray Coating Method.}

The air plasma spray is simply known as thermal spray coating process used to produce high quality coating in a combination of high temperature and high particle velocity. The term used to describe gas which has been raised in high temperature that ionizes and changes to electrically conductive [14]. The plasma spray coating technology uses to spraying of all any metallic surface are ceramic with wide range of materials with needed bond strength, while lowering the substrate. The major advantage of thermal coating technique is it provides to spray a wide range from metals to refractory ceramics, with those large and small components. And it has high corrosion protection and also in wear resistance. It had ability of withstand heat and oxidation resistance and also in temperature management. It had more conductivity and also electrical resistivity. In considering working temperature of four stroke single cylinder diesel engine, the piston crown coated with Aluminum oxide $\left(\mathrm{AL}_{2} \mathrm{O}_{3}\right)$ and Yttria stabilized zirconia (YSZ) in total of 250 microns [17-19]. In which 50 microns of bond coating and 200 microns of thermal barrier coating [20].

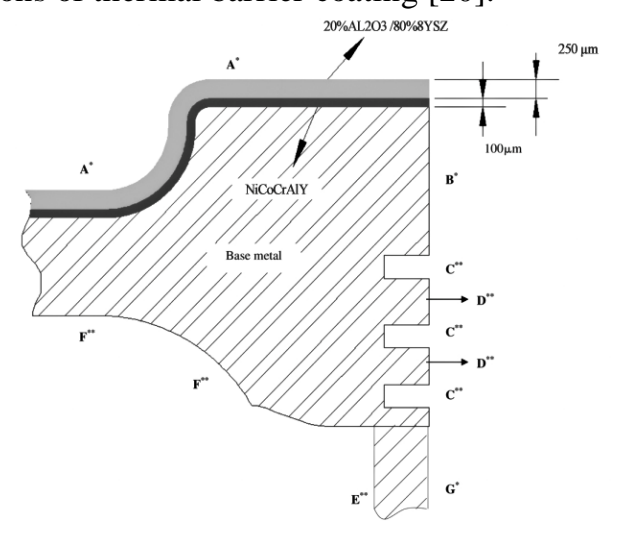

Figure 3: Coating materials in Piston crown

\section{EXPERIMENTATION}

Table 2: Specification of test engine

\begin{tabular}{|c|c|}
\hline Parameters & Position value \\
\hline Engine type & $\begin{array}{c}4 \text { stroke, Diesel } \\
\text { (computerized) }\end{array}$ \\
\hline Number of cylinders & 1 \\
\hline Model & TV1 \\
\hline Manufacturer & Kirloskar \\
\hline Cooling medium & Water cooled \\
\hline Break power & $5.2 \mathrm{kw}$ \\
\hline Cylinder bore & $87.5 \mathrm{~mm}$ \\
\hline Piston stroke & $110 \mathrm{~mm}$ \\
\hline Engine capacity & $661 \mathrm{cc}$ \\
\hline Compression ratio & $17.5: 1$ \\
\hline
\end{tabular}

The testing engine is kriloskar four strokes, single cylinder water cooled diesel engine 5.2kW Break power @ $1500 \mathrm{rpm}$ 
having compression ratio of 17.5:1 coupled to eddy current dynamometer. Cooling medium used is water cooled with the fuel tank capacity of 15 lit [24-25]. Piezo-electric pressure sensor is used to calculate the cylinder pressure with the range of 5500 PSI. Exhaust pipe is fitted with temperature sensor type RTD, PT100 and thermocouple and data acquisition device NI USB-6210, 16-bit, 250kS/s. The software used is "ENGINESOFT" (Engine performance analysis software) developed by Apex Innovation Pvt. Ltd. The materials selected are $\mathrm{Al}_{2} \mathrm{O}_{3}$ and $\mathrm{YSZ}\left(\mathrm{Y}_{2} \mathrm{O}_{3} \& \mathrm{ZrO}_{2}\right)$ with the composition of $20 \%$ of $\mathrm{Al}_{2} \mathrm{O}_{3}, 40 \%$ of $\mathrm{Y}_{2} \mathrm{O}_{3}$, and $40 \%$ of $\mathrm{ZrO}_{2}$. Air plasma spray technique is used to perform the coating in the piston crown with the total thickness of 250 microns, in which 50 microns for the bond coat of NiCrCoAlY compound and 200 microns of TBC material.

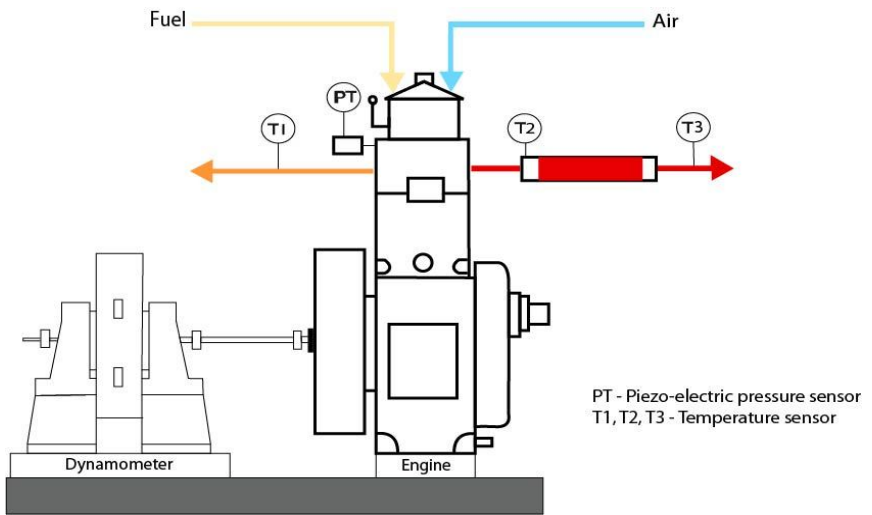

Figure 4: Diesel Engine Experimental setup kit

\section{RESULTS AND DISCUSSION}

Different performance parameters including brake thermal efficiency, brake specific fuel consumption, brake specific energy consumption and exhaust gas temperature defines the thermal barrier coating viability in Compression Ignition engines. Thus, they were analysed by varying the load from low load to part load and then to full load conditions. Its effect was also analysed by varying the compression ratio of the engine. The comparison of brake thermal efficiencies against brake mean effective pressure for uncoated piston and coated piston are depicted in Figure 5.

\section{CR 18 - BMEP vs BThEff}

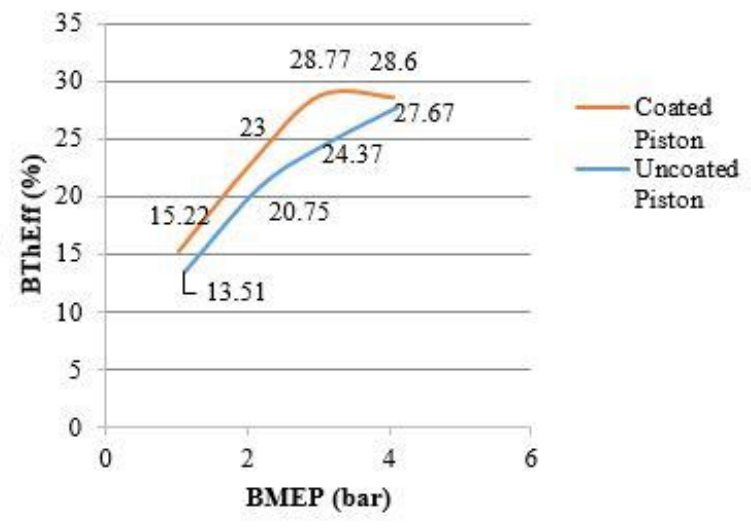

Figure 5. BMEP vs Brake Thermal efficiency for Coat and Uncoated Piston at Compression Ratio 18.
Brake thermal efficiency of a diesel engine is the efficiency with which the chemical energy of a fuel is converted into useful work. It can be seen that BTE increased with increases in Brake mean effective pressure. Brake Thermal Efficiency was increased might be because of the reduction in the frictional loses. It was also found that uncoated piston shows lesser BTE than the coated because of the reduction in the useful power derived from an engine due to the loss occurred as a result of heat rejection [21]. The Thermal Efficiency increase in coated piston for the compression ratio of CR18 was shown in the Figure 5.

It has been seen that the coated piston has shown greater brake thermal efficiency upto 3bar Mean Effective pressure after which it reduces might be because of increase in the engine load conditions. Uncoated piston shows lesser BTE than that of the diesel fuel which might be because of increase in the net heat released [22-23]. Piston with thermal barrier coating will give us the higher brake thermal efficiency due to the recovery of heat energy being devasted. The amount of fuel energy required to generate unit power in an hour is termed to be as Brake Specific Energy Consumption (BSEC). BSEC was plotted against the BMEP in the shown Figure 6.

\section{CR18 - BMEP vs BSEC}

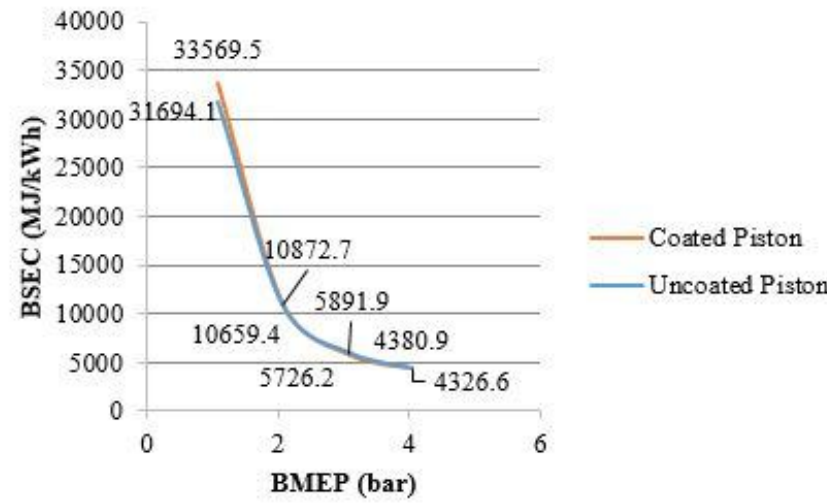

Figure 6. BMEP vs Brake Specific Energy Consumption for Coat and Uncoated Piston at Compression Ratio 18.

It shows that the BSEC was higher for lower load and decreases with an increase in the load. At higher compression ratio of CR18 both the coated and uncoated piston has exhibited BSEC value much similar to that of the Diesel which might be because of the increase in In-cylinder pressure which leads to better flame temperature.

\section{CONCLUSION}

Coated and Uncoated piston when tested on an Engine at a compression ratio 18, has revealed that the piston coated with Yttria Stabilized Zirconia has been more prominent for the utilization on commercial diesel engines. Coated piston has drastically shown the improved performance characteristics when compared with the uncoated piston. The brake thermal efficiency as well as the Brake Specific Energy Consumption was improved on Coated piston. Further study on improving the thickness of coating could reveal more data relevant to the performance, combustion and emission characteristics. 


\section{REFERENCES}

1. Z. Qin, C. Jia, W. Zhang, and L. Wang, "Investigations on ablation for highly-intensified diesel engine piston material," Case Stud. Therm. Eng., vol. 13, no. September 2018, p. 100371, 2019, doi: 10.1016/j.csite.2018.100371.

2. S. Saravanan, C. Ramesh Kumar, A. Pugazhendhi, and K. Brindhadevi, "Role of thermal barrier coating and porous medium combustor for a diesel engine: An experimental study," Fuel, vol. 280, no. May, p. 118597, 2020, doi: 10.1016/j.fuel.2020.118597.

3. U. Singh, J. Lingwal, A. Rathore, S. Sharma, and V. Kaushik, "Comparative analysis of different materials for piston and justification by simulation," Mater. Today Proc., vol. 25, no. xxxx, pp. 925-930, 2019, doi: 10.1016/j.matpr.2020.03.078.

4. S. Prakash, M. Prabhahar, O. P. Niyas, S. Faris, and C. Vyshnav, "Thermal barrier coating on IC engine piston to improve efficiency using dual fuel," Mater. Today Proc., no. xxxx, 2020, doi: 10.1016/j.matpr.2020.06.451.

5. T. Bao et al., 'Evolution of Al-Si-Cu alloy in piston of diesel engine during knock damage," Eng. Fail. Anal., vol. 112, no. March, p. 104501, 2020, doi: 10.1016/j.engfailanal.2020.104501.

6. E. Buyukkaya and M. Cerit, "Thermal analysis of a ceramic coating diesel engine piston using 3-D finite element method," Surf. Coatings Technol., vol. 202, no. 2, pp. 398-402, 2007, doi: 10.1016/j.surfcoat.2007.06.006.

7. E. Buyukkaya, "Thermal analysis of functionally graded coating AISi alloy and steel pistons," Surf. Coatings Technol., vol. 202, no. 16, pp. 3856-3865, 2008, doi: 10.1016/j.surfcoat.2008.01.034.

8. S. Caputo, F. Millo, G. Boccardo, A. Piano, G. Cifali, and F. C. Pesce, "Numerical and experimental investigation of a piston thermal barrier coating for an automotive diesel engine application," Appl. Therm. Eng., vol. 162, no. July, p. 114233, 2019, doi: 10.1016/j.applthermaleng.2019.114233.

9. V. Garud et al., "Performance and CombustionCharacteristics of Thermal Barrier Coated (YSZ) Low Heat Rejection Diesel Engine," Mater. Today Proc., vol. 4, no. 2, pp. 188-194, 2017, doi: 10.1016/j.matpr.2017.01.012.

10. S. Mohamed Abbas, A. Elayaperumal, and G. Suresh, "A study on combustion and performance characteristics of ceramic coated (PSZ/Al203) and uncoated piston - D.I engine," Mater. Today Proc., no.7(1), 2020, doi: 10.1016/j.matpr.2020.05.663.

11. P. Ramaswamy, V. Shankar, V. R. Reghu, N. Mathew, and S. Manoj Kumar, "A Model to Predict the Influence of Inconsistencies in Thermal Barrier Coating (TBC) Thicknesses in Pistons of IC Engines," Mater. Today Proc., vol. 5, no. 5, pp. 12623-12631, 2018, doi: 10.1016/j.matpr.2018.02.245.

12. V. R. Reghu, K. Lobo, A. Basha, P. Tilleti, V. Shankar, and P. Ramaswamy, "Protection offered by thermal barrier coatings to Al-Si alloys at high temperatures - A microstructural investigation," Mater. Today Proc., vol. 19, no. xxxx, pp. 676-681, 2019, doi: 10.1016/j.matpr.2019.07.752.

13. V. R. Reghu, N. Mathew, P. Tilleti, V. Shankar, and P. Ramaswamy, "Thermal Barrier Coating Development on Automobile Piston Material (Al-Si alloy), Numerical Analysis and Validation," Mater. Today Proc., vol. 22, pp. 1274-1284, 2019, doi: 10.1016/j.matpr.2020.01.420.

14. S. Shikhariya, B. Shimpi, A. Shinde, and S. U. Deokar, "Review on Thermal Barrier Coating in IC Engine," no. June, pp. 1114-1118, 2017, [Online]. Available: http://www.ijritcc.org.

15. A. Thibblin, S. Jonsson, and U. Olofsson, "Influence of microstructure on thermal cycling lifetime and thermal insulation properties of yttria-stabilized zirconia thermal barrier coatings for diesel engine applications," Surf. Coatings Technol., vol. 350, no. April, pp. 1-11, 2018, doi: 10.1016/j.surfcoat.2018.07.005.

16. H. Hazar, "Characterization of MoN coatings for pistons in a diesel engine," Mater. Des., vol. 31, no. 1, pp. 624-627, 2010, doi: 10.1016/j.matdes.2009.06.006.

17. Z. Yao and Z. Qian, "Thermal analysis of Nano ceramic coated piston used in natural gas engine," J. Alloys Compd., vol. 768, pp. 441-450, 2018, doi: 10.1016/j.jallcom.2018.07.278.

18. Z. Yao and W. Li, "Microstructure and thermal analysis of APS nano PYSZ coated aluminum alloy piston," J. Alloys Compd., vol. 812, p. 152162, 2020, doi: 10.1016/j.jallcom.2019.152162.

19. H. Zhao and F. Ye, "Investigation of sputtered WCN coating for diesel engine pistons 
applications," Vacuum, vol. 126, pp. 5-9, 2016, doi: 10.1016/j.vacuum.2016.01.006.

20. A. Gilbert, K. Kokini, and S. Sankarasubramanian, "Thermal fracture of zirconia-mullite composite thermal barrier coatings under thermal shock: A numerical study," Surf. Coatings Technol., vol. 203, no. 1-2, pp. 91-98, 2008, doi: 10.1016/j.surfcoat.2008.08.003.

21. L. Gu et al., "Influence of ceramic thickness on residual stress and bonding strength for plasma sprayed duplex thermal barrier coating on aluminum alloy," Surf. Coatings Technol., vol. 206, no. 21, pp. 4403-4410, 2012, doi: 10.1016/j.surfcoat.2012.04.070.

22. Z. Yao and W. Li, "Microstructure and thermal analysis of APS nano PYSZ coated aluminum alloy piston," J. Alloys Compd., vol. 812, p. 152162, 2020, doi: 10.1016/j.jallcom.2019.152162.

23. V. Kumar and K. Balasubramanian, "Progress update on failure mechanisms of advanced thermal barrier coatings: A review," Prog. Org. Coatings, vol. 90, pp. 54-82, 2016, doi: 10.1016/j.porgcoat.2015.09.019.

24. S. Salman and R. Ko, "Materials \& Design An investigation of different ceramic coating thermal properties," vol. 27, pp. 585-590, 2006, doi: 10.1016/j.matdes.2004.12.010.

25. S. Pal, A. Deore, A. Choudhary, V. Madhwani, and D. Vijapuri, "Analysis and experimental investigation of ceramic powder coating on aluminium piston," IOP Conf. Ser. Mater. Sci. Eng., vol. 263, no. 6, 2017, doi: $10.1088 / 1757-899 X / 263 / 6 / 062071$. 